\title{
Influence of printing speed on production of embossing tools using FDM 3D printing technology
}

\section{ABSTRACT}

Manufacturing of the embossing tools customary implies use of metals such as zinc, magnesium, copper, and brass. In the case of short run lengths, a conventional manufacturing process and the material itself represent a significant cost, not only in the terms of material costs and the need for using complex technological systems which are necessary for their production, but also in the terms of the production time. Alternatively, $3 D$ printing can be used for manufacturing similar embossing tools with major savings in production time and costs. However, due to properties of materials used in the 3D printing technology, expected results of embossing by 3D printed tools cannot be identical to metal ones. This problem is emphasized in the case of long run lengths and high accuracy requirement for embossed elements. The objective of this paper is primarily focused on investigating the influence of the printing speed on reproduction quality of the embossing tools printed with FDM (Fused Deposition Modelling) technology. The obtained results confirmed that printing speed as a process parameter affects the reproduction quality of the embossing tools printed with FDM technology: in the case of deposition rate of $90 \mathrm{~mm} / \mathrm{s}$ was noted the poorest dimensional accuracy in relation to the 3D model, which is more emphasised in case of circular and square elements. Elements printed with the highest printing speed have a greater dimensional accuracy, but with evident cracks on the surface.
Jelena Žarko, Gojko Vladić, Magdolna Pál, Sandra Dedijer

University of Novi Sad, Faculty of Technical Sciences, Department of Graphic Engineering and Design, Novi Sad, Serbia

Corresponding author: Jelena Žarko

e-mail:mravkae@gmail.com

First recieved: 16.09.2016

Accepted: 19.12.2016.

\section{KEY WORDS}

3D printing, Fused Deposition Modelling, embossing

\section{Introduction}

Embossing is a print finishing process which enables creating of raised or recessed images (e.g. logos or characters) on substrate surface using pressure and temperature. Embossing results in a raised or recessed surface, with the design higher or lower than the surrounding substrate area. In this process, usually two metal dies are used: one with raised image and another, counterdie with matching reverse image (Kipphan, 2001).

The most often used metals for dies manufacturing are zinc, magnesium, copper, and brass (Morlok et al., 2009). The material used for a specific application depends upon a number of factors. The manufacturing of metal embossing tools requires costly, but necessary technological systems. In case of long run lengths, their use is economically justified, but for small run lengths and personalized products, alternative, less expensive methods should be used. Besides, the current market demands for high reproduction quality, while maintaining environmental and more economical recycling objectives, with a faster product development and reduced time to market, should also be fulfilled. Having this in mind, it is suggested that 3D printing technology can be used for manufacturing similar embossing tools with major savings in production time and costs. So far the 3D printed embossing tools were used mainly for art reproductions and stamps for personal use, but there are no standard recommendations for the printing parameters that 
would guarantee the optimal results in embossing tools production using 3D printing technology (Webb, 2013).

"Additive Technologies" and "Additive Manufacturing" appoint a group of different technologies which enable creating of prototypes or finished products without the use of processing tools and equipment, solely on the basis of digital 3D CAD model. Their common feature is that the models are generated by applying or curing materials, layer-by-layer, based on which this technology is named.

Additive Technologies uses digital 3D CAD model to generate the physical model and, often, finished products with appropriate materials. In the literature there is also term "Rapid Prototyping", abbreviated RP (Nidagundi, Keshavamurthy \& Prakash, 2015).Fused Deposition Modeling (FDM) technology is one of the most widely used Additive Technology. The process involves layer-by-layer deposition of extruded material through a nozzle using feedstock filaments from a spool. There are variations in raster width of extruded material, depending on the nozzle diameter, which most commonly ranges between 0.2 and $0.6 \mathrm{~mm}$ (Gibson, Rosen \& Stucker, 2010). Some advantages of FDM technology are: solid, environmentally friendly material, ease of utilisation, ease of subsequent processing of the model, good mechanical and in the case of special materials good thermal characteristics of the part. The main disadvantages include the producing speed, resolution and lower surface quality.

\section{Critical parameters influencing the production quality of parts in FDM}

FDM process involves the application ranging from the prototype to the functional parts. The production process includes the following five (simple) steps: CAD model creating, conversion of CAD model into STL format, separation of STL format into the thin layers, building part layer by layer, cleaning and finishing. For the most functional application of FDM parts, precise dimensions, surface roughness and tensile strength of the part are considered to be important characteristics (Galantucci, Lavecchia \& Percoco, 2009).

These important characteristics of printed parts obtained by means of the FDM process, are influenced by a numerous production parameter, which can be divided into two groups: process parameters and printing parameters. Chouksey (2012) and Lee et al. (2004) reported that process parameters are: layer thickness, orientation, air gap, and raster angle, while printing parameters are: extrusion temperature, feed rate, flow rate, and raster width. Printing parameters may have different values according to various materials. With proper adjustment of the printing parameters, quality can be significantly improved without changing hardware and software.

\section{Parameters which have influence on dimensional accuracy}

In FDM process, raster width is a parameter which strongly influences dimensional accuracy, internal cavity and surface finishing of the final part. Raster width is described as the distance between the main coordinates of two nearby rasters. Górski, Kuczko \& Wichniarek, (2013) have studied effect of process parameters on dimensional accuracy of parts manufactured using FDM process. They have reported that orientation angle directly influences on repeatability and strength of FDM parts but is not related to dimensional accuracy. Sood, Ohdar \& Mahapatra (2010) have studied effect of layer thickness, part build orientation angle, raster angle, raster to raster gap and raster width together with the interaction of part build orientation angle. They concluded that all factors have some effect on the dimensional accuracy of FDM build part. Nancharaiah, Raju \& Raju, (2010) have explained an experimental design technique for finding the optimum surface finish and dimensional accuracy of a part built by the FDM process. They have investigated the effect of layer thickness, road width, raster angle and air gap on the surface finish and dimensional accuracy. They have found that the layer thickness and road width affect the surface quality and part accuracy in a large quantity. They have also stated that raster angle has no significant effect on part surface quality and dimensional accuracy unlike air gap, which has significant effect on dimensional accuracy and slight effect on surface quality of FDM parts.

In FDM process, extrusion temperature is one of the most effective parameter on final pattern of raster and layers formation and as a result, on amount of internal cavity. Yardimci et al. (1996) demonstrated that the temperature difference can affect the previous raster and/or the lower layer, making them change their positions. These changes are caused by the shrinkage of polymer and bring about hollows in the final part. Besides, Alhubail (2012) reported that polymer might be relaxed or expanded at higher temperatures, which means that an increase in dimensions with higher extrusion temperatures may occur.

\section{Parameters which have influence on surface finishing}

Vanitha, Nageswara \& Kedarmallik (2012) have investigated the effect of speed parameters on burnishing of parts built by FDM process. They have observed that increased spindle speed and depth of penetration have increased the surface hardness and reduced the surface roughness.

Vasudevarao et al. (2000) indicated that layer thickness and part orientation have significant effect on the surface roughness of fabricated parts. Anitha, Arunachalam, \& Radhakrishnan (2001) investigated the effect of lay- 
er thickness, road width and deposition speed on the surface roughness of component produced using FDM process. The results indicate that layer thickness is the most influencing process parameter affecting surface roughness followed by road width and deposition speed.

\section{Materials and method}

\section{D model}

Three embossing plates were prepared, with linear, circular and square raised elements (Figure 1). Featured elements were chosen because they are integral parts of the more complex forms, such are letters or more complex geometric images. The first plate had 6 line elements of initial widths: $0.2 \mathrm{~mm}, 0.5 \mathrm{~mm}, 1 \mathrm{~mm} 2 \mathrm{~mm}$, $3 \mathrm{~mm}$ and $4 \mathrm{~mm}$. The second plate contained circular elements of 6 initial diameters: $0.2 \mathrm{~mm}, 0.5 \mathrm{~mm}, 1 \mathrm{~mm} 2$ $\mathrm{mm}, 3 \mathrm{~mm}$ and $4 \mathrm{~mm}$. The third plate was prepared with square elements of 6 initial side lengths: $0.2 \mathrm{~mm}, 0.5$ $\mathrm{mm}, 1 \mathrm{~mm} 2 \mathrm{~mm}, 3 \mathrm{~mm}$ and $4 \mathrm{~mm}$. The shoulder angle of the elements was $30^{\circ}$. Height of the elements was 1 $\mathrm{mm}$. The 3D solid models of test embossing plates (die) were modelled in Rhinoceros version 5 (die with line elements) and CATIA software version v5 (dies with circular and square elements) and exported as STL file, while STL file was imported to MakerBot Desktop software to prepare the printing process.

a)

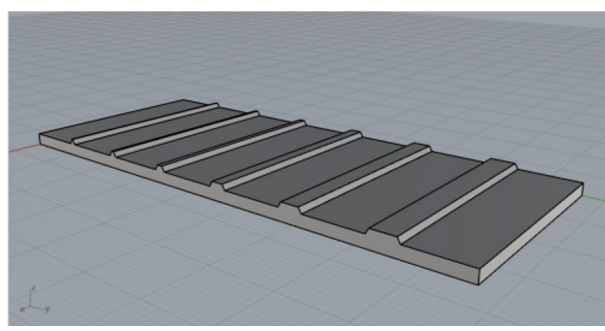

b)

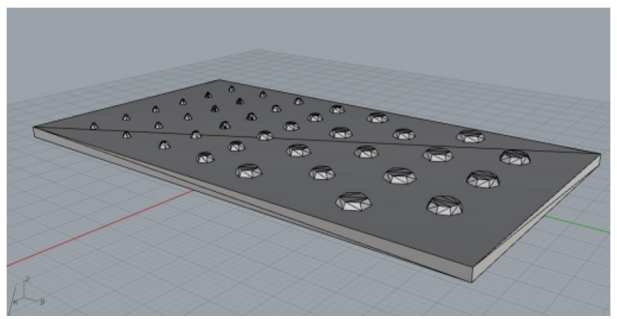

c)

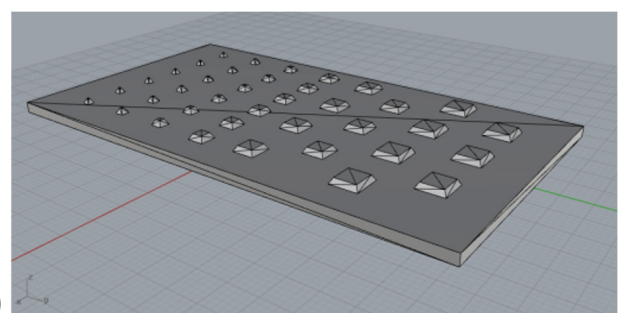

» Figure 1: 3D CAD model of a) line elements b) circular elements and c) square elements

\section{D printing setup}

For the purpose of this investigation, MakerBot Replicator Fifth Generation has been used as a FDM 3D printer. The parameters used for printing of embossing tools were: $100 \%$ infill, 0.20 layer height, extrusion temperature of $210{ }^{\circ} \mathrm{C}$ and three printing speeds: 10 $\mathrm{mm} / \mathrm{s}, 90 \mathrm{~mm} / \mathrm{s}$ and $200 \mathrm{~mm} / \mathrm{s}$. These speeds are chosen as the minimum $(10 \mathrm{~mm} / \mathrm{s})$ and maximum $(200 \mathrm{~mm} / \mathrm{s})$ values that Makerbot Replicator supports, and $90 \mathrm{~mm} / \mathrm{s}$ as the optimal speed value recommended by the manufacturer (Makerbot, 2016).

\section{Methodology}

The printed elements were analyzed using visual quality assessment and quantitative measurements. For visual quality assessment microscopic images, captured with Veho VMS-001 portable USB digital microscope (magnification of 20x) were used. Images were taken from the top and front view of the embossing plates.

The quantitative measurements were done using microscopic images captured with ViTiny VT-300 portable USB digital microscope (magnification of 10x; filter mode inverted) in open source software for image processing- ImageJ. The line elements were characterized from the aspect of line width, perimeter, area and aspect ratio, while circular and square elements were characterized from the aspect of elements perimeter, area and aspect ratio.

Line elements were analyzed with software tool for measuring the distance between two points on the image, in order to measure the width of the element. For the analysis of the perimeter and surface area, the surface of interest was segmented using Otsu algorithm, and then, using software built-in functions for area and perimeter calculation, area and perimeter of the elements was determined. Square and round elements were also analyzed after image segmentation using Otsu algorithm. The aspect ratio of the elements was calculated using software built-in function. The measurement results of perimeter and surface area are processed through perimeter and area index, indicating the changes in reproduced element area/perimeter in relation to the initially set value. They were calculated as follows:

$I_{p}=P_{m} / P_{\text {in }}$

Where: $I_{p}$ - perimeter index, $\mathrm{P}_{m}$ - mean perimeter value of the measured elements, $\mathrm{P}_{\text {in }}$ - initial perimeter value of the elements.

$I_{a}=A_{m} / A_{\text {in }}$

Where: $I_{a}$ - area index, $A_{m}$ - mean area value of the measured elements, $A_{\text {in }}$ - initial area value of the elements. 


\section{Results and discussion}

\section{Visual quality assessment of 3D printed elements}

Assessment of line elements

Analysing images of the elements reproduced with printing speed of $10 \mathrm{~mm} / \mathrm{s}$, it was noted that elements are visually similar to the initial 3D CAD models, with no surface deformations and non-uniformities (Figure 2).
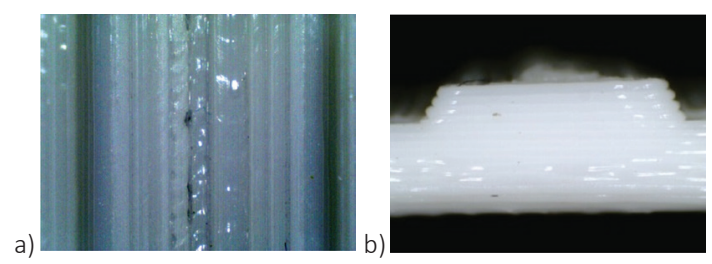

» Figure 2: Example - microscopic images of $4 \mathrm{~mm}$ line (magnification of 20x; printing speed $10 \mathrm{~mm} / \mathrm{s}$ ): a) top view, b) front view

Analysing images of elements reproduced with printing speed of $90 \mathrm{~mm} / \mathrm{s}$, the poorest reproduction was noted for $0.2 \mathrm{~mm}$ (Figure 3) and $0.5 \mathrm{~mm}$ (Figure 4) lines. .
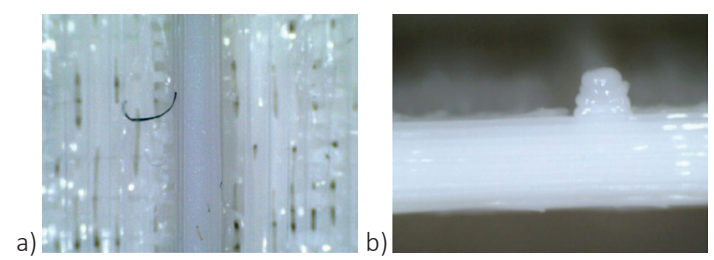

» Figure 3: Microscopic images of $0.2 \mathrm{~mm}$ line (magnification of 20x; printing speed $90 \mathrm{~mm} / \mathrm{s}$ ): a) top view, b) front view
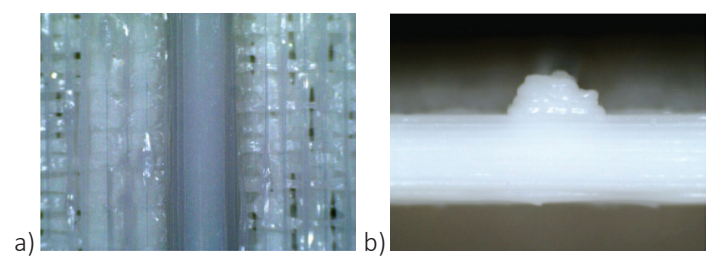

» Figure 4: Microscopic images of $0.5 \mathrm{~mm}$ line (magnification of 20x; printing speed $90 \mathrm{~mm} / \mathrm{s}$ ): a) top view, b) front view

Since MakerBot Replicator Fifth Generation can print lines with minimum width of $0.2 \mathrm{~mm}$, it was expected that for higher printing speeds, reproduction of narrower lines will be of lower quality. The top view of the elements indicates the surface deformations and non-uniformity of the wider lines, starting from $2 \mathrm{~mm}$ line. Surface deformations are the most prominent on 4 $\mathrm{mm}$ line (Figure 5)
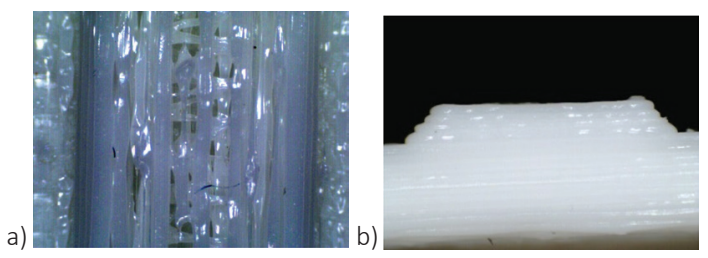

» Figure 5: Microscopic images of $4 \mathrm{~mm}$ line (magnification of 20x; printing speed $90 \mathrm{~mm} / \mathrm{s}$ ): a) top view, b) front view

Analysing images reproduced with printing speed of $200 \mathrm{~mm} / \mathrm{s}$, it was noted that elements are visually similar to the initial 3D CAD models (Figure 6), from both front and top view, but with surface deformations and non-uniformities starting with $2 \mathrm{~mm}$ line. Surface deformations are the most prominent on $4 \mathrm{~mm}$ line (Figure 7).
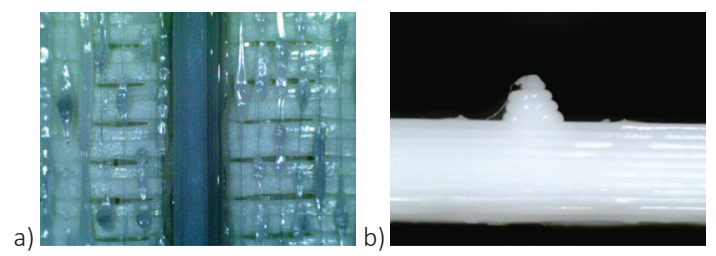

» Figure 6: Example - microscopic images of $0.2 \mathrm{~mm}$ line (magnification of 20x; printing speed $200 \mathrm{~mm} / \mathrm{s}$ ): a) top view, b) front view
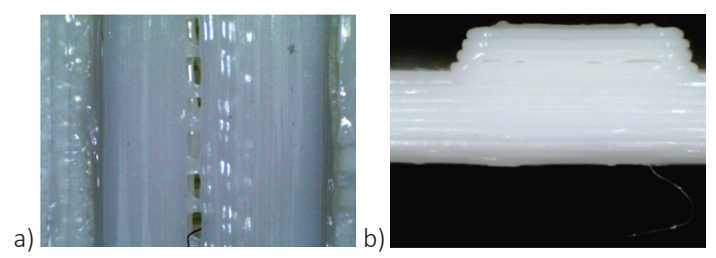

» Figure 7: Microscopic images of $4 \mathrm{~mm}$ line (magnification of 20x; printing speed $200 \mathrm{~mm} / \mathrm{s}$ ): a) top view, b) front view

These surface deformations are greater and more prominent compared to surface deformations detected on elements reproduced with printing speed of $90 \mathrm{~mm} / \mathrm{s}$.

\section{Assessment of circular elements}

Analysing microscopic images of the circular elements (top view), regardless of printing speed, the poorest reproduction was noted for $0.2 \mathrm{~mm}$ (Figure 8), $0.5 \mathrm{~mm}$ (Figure 9) and $1 \mathrm{~mm}$ (Figure 10) circles. 

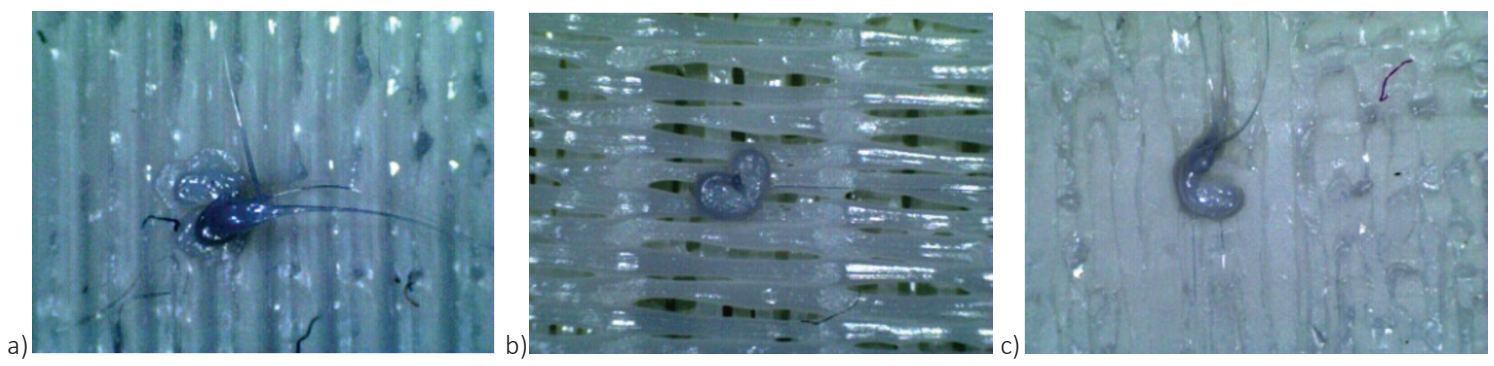

» Figure 8: Microscopic images of $0.2 \mathrm{~mm}$ circle (top view, magnification of 20x) and printing speed of: a) $10 \mathrm{~mm} / \mathrm{s}, \mathrm{b}$ ) $90 \mathrm{~mm} / \mathrm{s}$ and c) $200 \mathrm{~mm} / \mathrm{s}$
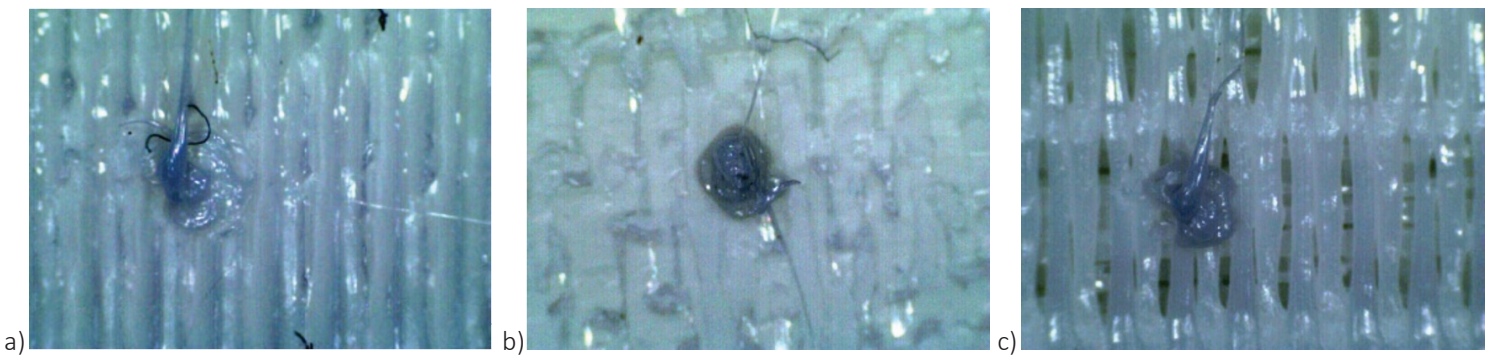

» Figure 9: Microscopic images of $0.5 \mathrm{~mm}$ circle (top view, magnification of 20x) and printing speed of: a) $10 \mathrm{~mm} / \mathrm{s}, \mathrm{b}$ ) $90 \mathrm{~mm} / \mathrm{s}$ and c) $200 \mathrm{~mm} / \mathrm{s}$
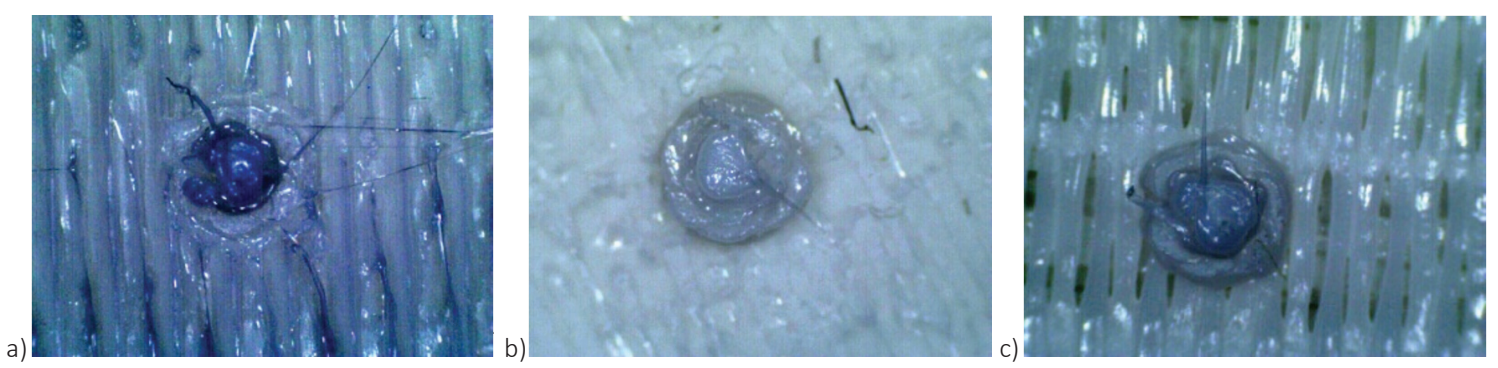

» Figure 10: Microscopic images of $1 \mathrm{~mm}$ circle (top view, magnification of 20x) and printing speed of: a) $10 \mathrm{~mm} / \mathrm{s}$, b) $90 \mathrm{~mm} / \mathrm{s}$ and c) $200 \mathrm{~mm} / \mathrm{s}$
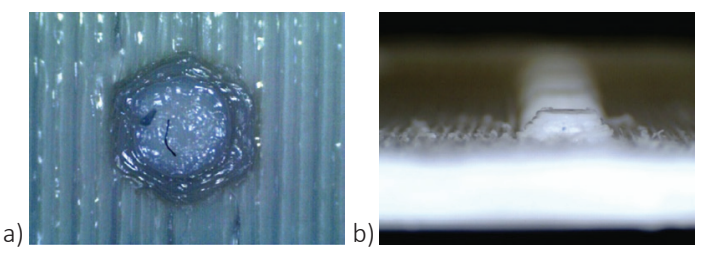

» Figure 11: Microscopic images of $2 \mathrm{~mm}$ circle (printing speed $10 \mathrm{~mm} / \mathrm{s}$, magnification of 20x): a) top view, b) front view

Visually, first the most precisely printed element is circle with diameter of $2 \mathrm{~mm}$ (Figures 11-13).

The surface deformations and non-uniformities were not detected, but it is noticed that the reproduced elements have hexagonal shape, which represents a circle of low resolution. This occurred due to the tessellation NURBS in Poly process during modelling elements in $3 \mathrm{D}$ CAD program.
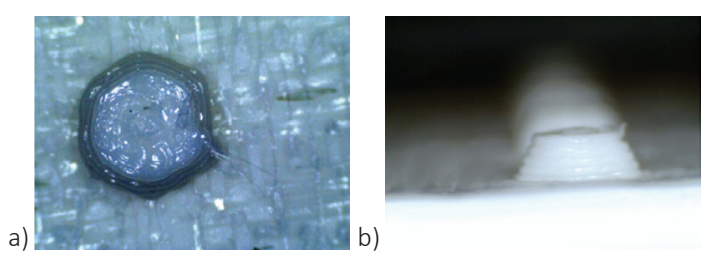

» Figure 12: Microscopic images of $2 \mathrm{~mm}$ circle (printing speed $90 \mathrm{~mm} / \mathrm{s}$, magnification of 20x): a) top view, b) front view
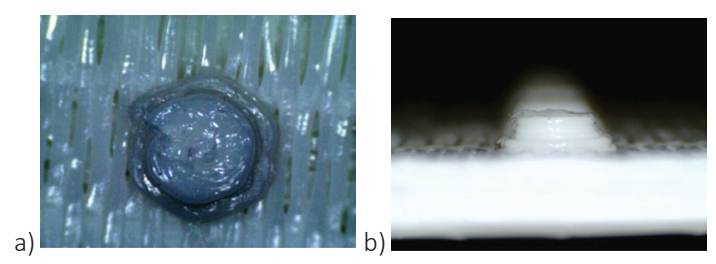

Figure 13: Microscopic images of $2 \mathrm{~mm}$ circle (printing speed $200 \mathrm{~mm} / \mathrm{s}$, magnification of 20x): a) top view, b) front view 

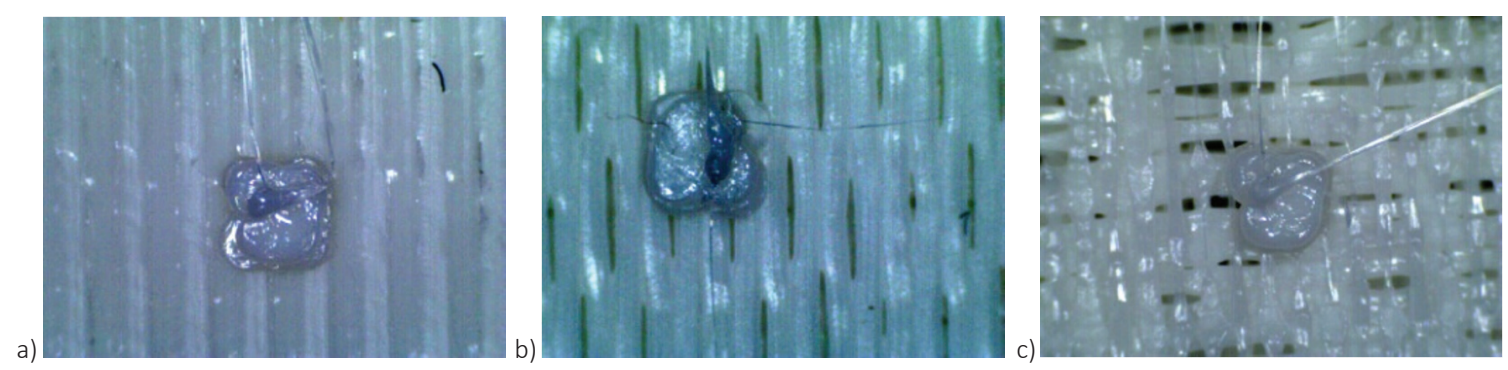

» Figure 14: Microscopic images of $0.2 \mathrm{~mm}$ square (top view, magnification of 20x) and printing speed of: a) $10 \mathrm{~mm} / \mathrm{s}$, b) $90 \mathrm{~mm} / \mathrm{s}$ and c) $200 \mathrm{~mm} / \mathrm{s}$
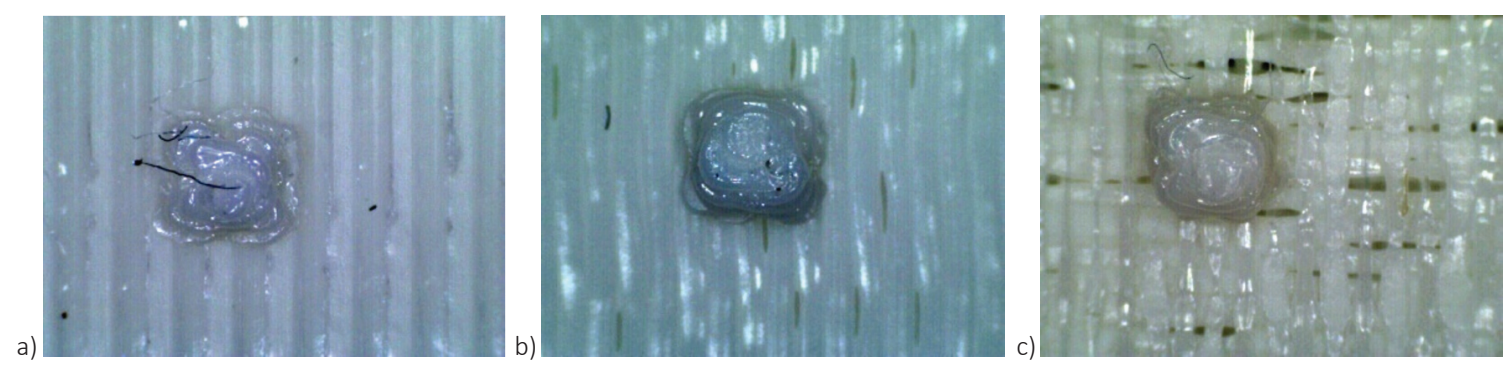

» Figure 15: Microscopic images of $0.5 \mathrm{~mm}$ square (top view, magnification of 20x) and printing speed of: a) $10 \mathrm{~mm} / \mathrm{s}$, b) $90 \mathrm{~mm} / \mathrm{s}$ and c) $200 \mathrm{~mm} / \mathrm{s}$
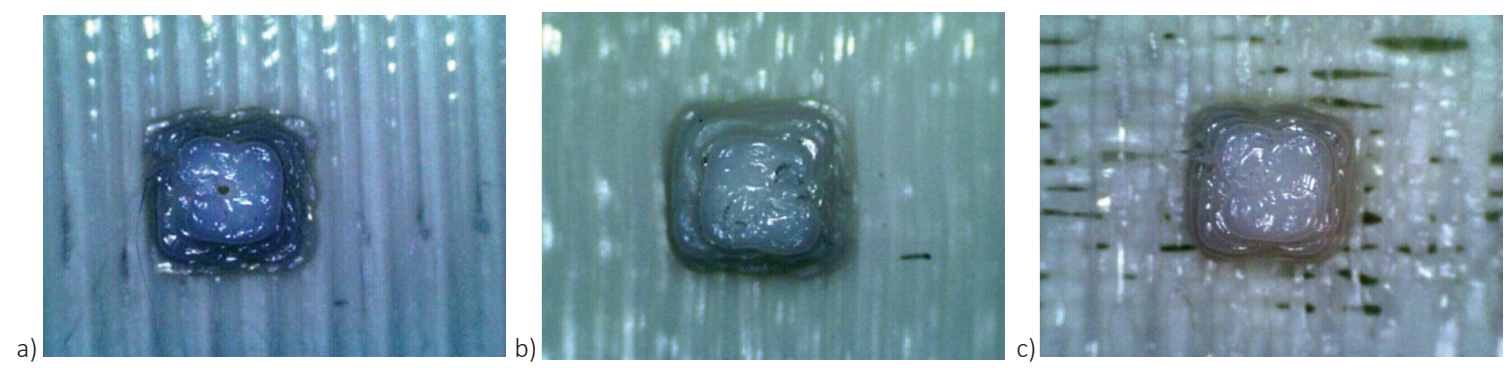

» Figure 16: Microscopic images of $1 \mathrm{~mm}$ square (top view, magnification of 20x) and printing speed of: a) $10 \mathrm{~mm} / \mathrm{s}$, b) $90 \mathrm{~mm} / \mathrm{s}$ and c) $200 \mathrm{~mm} / \mathrm{s}$

\section{Assessment of square elements}

Analysing microscopic images of the square elements (top view), regardless of printing speed, the poorest reproduction was found for $0.2 \mathrm{~mm}$ (Figure 14), $0.5 \mathrm{~mm}$ (Figure 15) and $1 \mathrm{~mm}$ (Figure 16) elements. Visually, first the most precisely printed element is $2 \mathrm{~mm}$ square (Figures 17-19). The top view of the elements indicates that there are no surface deformations and non-uniformities.
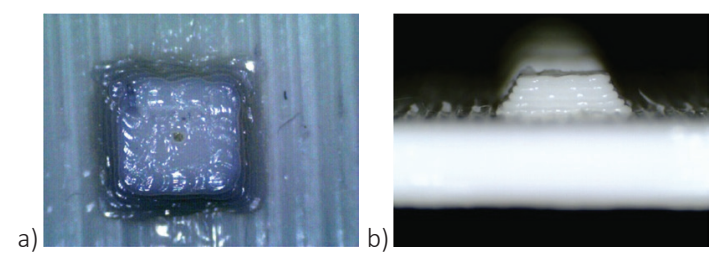

» Figure 17: Microscopic images of $2 \mathrm{~mm}$ square (printing speed $10 \mathrm{~mm} / \mathrm{s}$, magnification of 20x): a) top view, b) front view
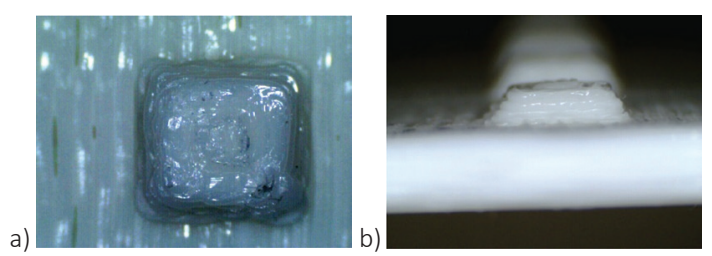

» Figure 18: Microscopic images of $2 \mathrm{~mm}$ square (printing speed $90 \mathrm{~mm} / \mathrm{s}$, magnification of 20x): a) top view, b) front view
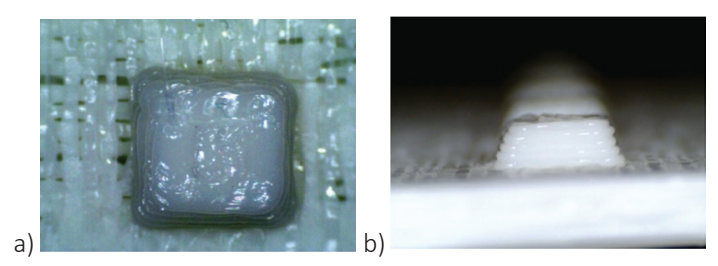

» Figure 19: Microscopic images of $2 \mathrm{~mm}$ square (printing speed $200 \mathrm{~mm} / \mathrm{s}$, magnification of 20x): a) top view, b) front view 


\section{Quantitative analysis of 3D printed elements}

Analysis of line elements

As it can be seen in Table 1, for all printing speeds, regardless of the initially defined line width, all lines are reproduced with higher width value. The results indicate that with a decrease in printing speed, even greater deviation of reproduced line width compared to their initial value can be expected. Also, it is noticed that regardless of the applied printing speed, the deviations are lower for initially wider lines.

In Table 2 are presented values of perimeter and area index for all lines and all printing speeds. It can be seen that at all printing speeds and regardless of the initially defined line width, all lines are reproduced with an increasement in perimeter and area $\left(I_{p}\right.$ and $\left.I_{a}>1\right)$. Values of perimeter index of line elements deposited at printing speed of $10 \mathrm{~mm} / \mathrm{s}$ indicate that the element has lower increasement in perimeter as the initial line width increases. This trend is also noticed in the case of line area but for all printing speeds.

\section{Table 1}

Results of line width measurements

\begin{tabular}{c|c|c|c}
\hline \multirow{2}{*}{$\begin{array}{l}\text { Initial line } \\
\text { width }\end{array}$} & \multicolumn{3}{|c}{ Measured line width } \\
\cline { 2 - 4 } [mm] & \multicolumn{3}{|c}{ Printing speed [mm/s] } \\
\cline { 2 - 4 } & 10 & 90 & 200 \\
\hline 0.2 & 0.362 & 0.409 & 0.385 \\
\hline 0.5 & 0.716 & 0.763 & 0.705 \\
\hline 1 & 1.213 & 1.139 & 1.172 \\
\hline 2 & 2.496 & 2.121 & 2.125 \\
\hline 3 & 3.366 & 3.058 & 3.192 \\
\hline 4 & 4.220 & 4.074 & 4.057 \\
\hline
\end{tabular}

The values presented in the Table 2 indicate that with the increase in printing speed greater increasment in area of reproduced line elements can be expected.

\section{Table 2}

Results of line perimeter and area index

\begin{tabular}{c|c|c|c|c|c|c}
\hline \multirow{2}{*}{$\begin{array}{l}\text { Initial line width } \\
{[\mathrm{mm}]}\end{array}$} & \multicolumn{7}{|c}{ Measured line width } \\
\cline { 2 - 7 } & \multicolumn{7}{|c}{ Printing speed [mm/s] } \\
\cline { 2 - 7 } & 10 & 90 & 200 & 10 & 90 & 200 \\
\hline 0.2 & 0.362 & 0.409 & 0.385 & 1.767 & 2.083 & 2.403 \\
\hline 0.5 & 0.716 & 0.763 & 0.705 & 1.521 & 1.636 & 1.471 \\
\hline 1 & 1.213 & 1.139 & 1.172 & 1.181 & 1.155 & 1.247 \\
\hline 2 & 2.496 & 2.121 & 2.125 & 1.205 & 1.085 & 1.001 \\
\hline 3 & 3.366 & 3.058 & 3.192 & 1.079 & 1.029 & 1.002 \\
\hline 4 & 4.220 & 4.074 & 4.057 & 1.031 & 1.020 & 1.001 \\
\hline
\end{tabular}

\section{Table 3}

Results of circular elements aspect ratio, perimeter and area index

\begin{tabular}{c|c|c|c|c|c|c|c|c|c}
\hline \multirow{2}{*}{$\begin{array}{l}\text { Initial circle } \\
\text { diameter } \\
\text { [mm] }\end{array}$} & \multicolumn{3}{|c|}{ Perimeter index $-_{\mathrm{p}}$} & \multicolumn{3}{c|}{ Area index $-\mathrm{I}_{\mathrm{a}}$} & \multicolumn{3}{c}{ Aspect ratio } \\
\cline { 2 - 10 } & \multicolumn{9}{|c|}{ Printing speed [mm/s] } \\
\cline { 2 - 11 } & 10 & 90 & 200 & 10 & 90 & 200 & 10 & 90 & 200 \\
\hline $\mathbf{2}$ & 1.099 & 1.744 & 1.176 & 0.952 & 1.221 & 1.088 & 1.050 & 1.045 & 1.062 \\
\hline $\mathbf{3}$ & 1.171 & 1.794 & 1.150 & 1.006 & 1.220 & 1.020 & 1.048 & 1.033 & 1.034 \\
\hline $\mathbf{4}$ & 1.258 & 1.804 & 1.197 & 0.973 & 1.234 & 0.936 & 1.060 & 1.038 & 1.046 \\
\hline
\end{tabular}

\section{Table 4}

Results of square elements aspect ratio, perimeter and area index

\begin{tabular}{|c|c|c|c|c|c|c|c|c|c|}
\hline \multirow{3}{*}{$\begin{array}{l}\text { Initial } \\
\text { element } \\
\text { side length } \\
\text { [mm] }\end{array}$} & \multicolumn{3}{|c|}{ Perimeter index $-I_{p}$} & \multicolumn{3}{|c|}{ Area index $-I_{a}$} & \multicolumn{3}{|c|}{ Aspect ratio } \\
\hline & \multicolumn{9}{|c|}{ Printing speed $[\mathrm{mm} / \mathrm{s}]$} \\
\hline & 10 & 90 & 200 & 10 & 90 & 200 & 10 & 90 & 200 \\
\hline 2 & 1.112 & 1.783 & 1.233 & 1.078 & 1.587 & 1.345 & 1.067 & 1.077 & 1.083 \\
\hline 3 & 1.118 & 1.490 & 1.125 & 0.947 & 1.317 & 1.157 & 1.040 & 1.083 & 1.040 \\
\hline 4 & 1.180 & 1.474 & 1.175 & 1.001 & 1.190 & 1.054 & 1.036 & 1.052 & 1.038 \\
\hline
\end{tabular}


Analysis of circular elements

In Table 3 are presented the results of perimeter index, area index and aspect ratio for circular elements at all printing speeds. Elements of initial diameter value less than $2 \mathrm{~mm}$ are not properly reproduced, therefore the results are presented for circles of initial diameter of $2 \mathrm{~mm}, 3 \mathrm{~mm}$ and $4 \mathrm{~mm}$.

Values of perimeter index of circular elements deposited at printing speed of $90 \mathrm{~mm} / \mathrm{s}$ indicate increasment in perimeter value up to $80 \%$, while elements deposited at printing speed of $10 \mathrm{~mm} / \mathrm{s}$ and $200 \mathrm{~mm} / \mathrm{s}$ had increasment up to $26 \%$. Results of area index for circular elements deposited at printing speed of $90 \mathrm{~mm} / \mathrm{s}$, indicate increasment in surface up to $23 \%$, while elements deposited at printing speed of $10 \mathrm{~mm} / \mathrm{s}$ and $200 \mathrm{~mm} / \mathrm{s}$ indicates that the increasment is up to $9 \%$. Element with initial diameter value of $2 \mathrm{~mm}$ deposited at printing speed of $10 \mathrm{~mm} / \mathrm{s}$ and element of initial diameter value of $4 \mathrm{~mm}$ deposited at printing speed of $10 \mathrm{~mm} / \mathrm{s}$ and 200 $\mathrm{mm} / \mathrm{s}$ has decreasment in area up to $6 \%$. Aspect ratio values, regardless of the initial diameter value and printing speed, indicates that elements are regular hexagons.

\section{Analysis of square elements}

In Table 4 are presented results of perimeter index and area index and aspect ratio for square elements at all printing speeds. Elements of initial side length less than $2 \mathrm{~mm}$ were not properly reproduced, therefore the results are presented for only for squares with side length of $2 \mathrm{~mm}, 3 \mathrm{~mm}$ and $4 \mathrm{~mm}$.

The obtained results of perimeter index for square elements deposited at printing speed of $90 \mathrm{~mm} / \mathrm{s}$ indicate increasment in perimeter up to $78 \%$, while at printing speed of $10 \mathrm{~mm} / \mathrm{s}$ and $200 \mathrm{~mm} / \mathrm{s}$ the increasments are up to $23 \%$. The area index values indicate increasement in element area up to 58\%, regardless of printing speed. The exception is square element of $3 \mathrm{~mm}$ and printing speed of $10 \mathrm{~mm} / \mathrm{s}$, which has decreasement of area value up to $5 \%$. Also, it is noticed that, regardless of the applied printing speed, changes in area and perimeter values are smaller for initially larger elements. The aspect ratio values, regardless of the initial element dimension and printing speed indicates that elements are regular squares.

\section{Conclusions}

The research of 3D printed embossing dies, presented in this paper, has shown that FDM 3D printing technology may be used for embossing tools production with certain limitations. Smaller elements cannot be reproduced with great precision. Both visual and quantitative assessments have shown that with increase of element width, diameter or side length decreases the possibility in width, perimeter or area deviations.

Based on the visual and quantitative assessments, it can be concluded that changes in printing speed affects the quality of line, circle and square elements reproduction and their dimensional accuracy.

In the case of deposition rate of $90 \mathrm{~mm} / \mathrm{s}$ was noted the poorest dimensional accuracy in relation to the $3 \mathrm{D}$ model, which is more emphasised in case of circular and square elements. Elements printed with the highest printing speed have the best dimensional accuracy, but with evident cracks on the surface of wider line elements.

In the case of square and circular elements, reproduction was successful only for elements whose diameter or side is greater than $2 \mathrm{~mm}$. This could represent a problem in reproduction of finer elements, such as typographical elements, especially types with serifs. It is necessary to find appropriate values for other variable printing parameters that would guarantee the optimal results in dimensional accuracy and surface quality, with the aim of finding optimal parameters for making finer and thinner elements of the 3D printed embossing tool. Further research will be aimed towards detailed surface characterisation of embossing elements as well as their mechanical properties.

\section{Acknowledgement}

This work was supported by the Serbian Ministry of Science and Technological Development, Grant No.: 35027 "The development of software model for improvement of knowledge and production in graphic arts industry".

\section{References}

Alhubail, M. (2012) Statistical-based optimization of process parameters of Fused Deposition Modelling for improved quality. PhD thesis. University of Portsmouth.

Anitha, R., Arunachalam, S. \& Radhakrishnan, P. (2001) Critical parameters influencing the quality of prototypes in fused deposition modelling. Journal of Materials Processing Technology. 118 (1-3), 385-388. Available from: doi: 10.1016/S0924. 0136(01)00980-3 [Accessed 25th June 2016].

Chouksey, A. (2012) Study of parametric optimization of Fused Deposition Modelling using response surface methodology. BsC thesis. National Institute of Technology Rourkela.

Galantucci, L. M., Lavecchia, F. \& Percoco, G. (2009) Experimental study aiming to enhance the surface finish of fused deposition modeled parts. CIRP Annals -Manufacturing Technology. 58 (1), 
189-192. Available from: 10.1016/j.cirp.2009.03.071 [Accessed 25th January 2016].

Gibson, I., Rosen, D. W. \& Stucker, B. (2010) Additive Manufacturing Technologies: Rapid Prototyping to Direct Digital Manufacturing. New York, Springer.

Górski, F., Kuczko, W. \& Wichniarek, R. (2013) Influence of process parameters on dimensional accuracy of parts manufactured using fused deposition modelling technology. Advances in Science and Technology Research Journal. 7 (19), 27-35. Available from: doi: 10.5604/20804075.1062340 [Accessed 09th January 2016].

Kipphan, H. (2001) Handbook of Print Media. New York, Springer.

Lee, C. W., Chua, C. K., Cheah, C. M., Tan, L. H. \& Feng, C. (2004) Rapid investment casting: direct and indirect approaches via fused deposition modelling. The International Journal of Advanced Manufacturing Technology. 23 (1), 93-101. Available from: doi: 10.1007/ s00170-003-1694-y [Accessed 09th March 2016].

Makerbot. (2016) The all-new Makerbot Replicatior +. Available from: http://store. makerbot. com/replicator [Accessed 23th June 2016].

Morlok, F., Beckmann, T., Zehentbauer, M. \& Jäger, U. (2009) Extra: encyclopedia of experimental print finishing. Basel, Birkhäuser.

Nancharaiah, T., Raju, D.R. \& Raju, V.R. (2010) An experimental investigation on surface quality and dimensional accuracy of FDM components. International Journal on Emerging Technologies. 1 (2), 106-111.

Nidagundi, V. B., Keshavamurthy, R. \& Prakash, C. P. S. (2015) Studies on Parametric Optimization for Fused Deposition Modelling Process. Materials Today: Proceedings. 2 (4-5),
1691-1699. Available from: doi: 10.1016/j. matpr.2015.07.097 [Accessed 16th March 2016]. Sood, A. K., Ohdar, R. K. \& Mahapatra, S. S. (2010) Grey Taguchi Method for Improving Dimensional Accuracy of FDM Process. In: Indus Business Academy \& AIMS International- The Association of Indian Management Scholars International and Indian Institute of Management Bangalore. Proceedings of the AIMS International Conference on Value-Based Management, 11-13 August 2010. Dev Sanskriti Vishwavidyalaya Haridwar, India. Huston, AIMS International. pp. 608-613.

Vanitha, M., Nageswara, R. A. \& Kedarmallik, M. (2012) Optimization of Speed Parameters in Burnishing of Samples Fabricated by FDM. International Journal of Mechanical and Industrial Engineering. 2 (2), 10-12.

Vasudevarao, B., Natarajan, D. P., Henderson, M. \& Razdan, A. (2000) Sensitivity Of RP Surface Finish To Process Parameter Variation. Available from: http://sffsymposium.engr.utexas. edu/Manuscripts/2000/2000-31-Vasudevarao.pdf [Accessed 16th March 2016].

Webb, J. (2013) How to Make and Use 3D-Printed Relief, Intaglio and Stencil Plates for Printmaking. Available from: http://jason-webb.info/2013/03/how-tomake-and-use-3d-printed-relief-intaglio-and-stencilplates-for-printmaking/ [Accessed 23th June 2016].

Yardimci, M. A., Selcuk, I. G., Agarwala, M. \& Danforth, S. C. (1996) Part Quality Prediction Tools for Fused Deposition Processing. Available from: https://sffsymposium.engr.utexas. edu/Manuscripts/1996/1996-62-Yardimci. pdf [Accessed 16th March 2016].

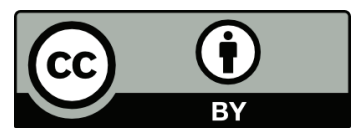

(C) 2017 Authors. Published by the University of Novi Sad, Faculty of Technical Sciences, Department of Graphic Engineering and Design. This article is an open access article distributed under the terms and conditions of the Creative Commons Attribution license 3.0 Serbia (http://creativecommons.org/licenses/by/3.0/rs/). 